\title{
Calculation Method for the Critical Thickness of a Karst Cave Roof at the Bottom of a Socketed Pile
}

\author{
Nie Qingke, ${ }^{1,2}$ Li Xilai, ${ }^{3,4}$ Yuan Wei, ${ }^{3,4}$ Wang Anli ${ }^{1},{ }^{5}$ Wang Wei, ${ }^{1,2}$ \\ Jia Xiangxin, ${ }^{1,2}$ and Shang Weidong ${ }^{1,2}$ \\ ${ }^{1}$ China HeBei Construction and Geotechnical Investigation Group Ltd., Shijiazhuang 050227, China \\ ${ }^{2}$ Hebei Research Center of Geotechnical Engineering Technology, Shijiazhuang 050227, China \\ ${ }^{3}$ School of Civil Engineering, Shijiazhuang Tiedao University, Shijiazhuang 050043, China \\ ${ }^{4}$ State Key Laboratory of Mechanical Behavior and System Safety of Traffic Engineering Structures, \\ Shijiazhuang Tiedao University, Shijiazhuang 050043, China \\ ${ }^{5}$ Guizhou Engineering Technology Research Center for Exploitation and Utilization of Water Resources in Karst Region, \\ Guiyang 550002, China
}

Correspondence should be addressed to Wang Anli; yuanweisuper001@126.com

Received 5 November 2021; Accepted 27 November 2021; Published 16 December 2021

Academic Editor: Bingxiang Yuan

Copyright (c) 2021 Nie Qingke et al. This is an open access article distributed under the Creative Commons Attribution License, which permits unrestricted use, distribution, and reproduction in any medium, provided the original work is properly cited.

The thickness of a karst cave roof at the bottom of a socketed pile plays an important role in the vertical bearing capacity of the socketed pile in the karst region. In practice, its thickness is simply recommended to be not less than 3 times the diameter of the socketed pile, regardless of the geological conditions and the size of the cave itself. In this study, we present an approach for calculating the critical thickness-to-diameter ratio of a karst cave roof $\eta(\eta=h / d$, the ratio of karst cave roof thickness to pile diameter) based on the generalized Hoek-Brown criterion by virtue of the limit analysis method, which considers the pile tip load, hardness degree of the intact rock, and rock mass quality. The analysis results show that less load at the bottom of the pile, higher quality of rock mass, and more hard rock all lead to a smaller critical thickness-diameter ratio, whereas the critical thickness-todiameter ratio is greater. The validity of the proposed method is verified through a physical model test.

\section{Introduction}

Pile foundations have been widely used in engineering construction in karst areas because of their strong load transfer capacity, which can effectively reduce the uneven settlement of the foundation and reduce the adverse impact of a karst cave on the foundation to a certain extent [1]. The key problem with pile foundations in karst areas is the calculation of their vertical bearing capacity. For a socketed pile with an underlying karst cave, the thickness of the karst cave roof is directly related to the bearing characteristics of the foundation pile and thus the engineering costs. Selecting an appropriate safety thickness can ensure considerable economic and social benefits to the whole project. Therefore, many researchers and engineers have focused on the stability of karst cave roofs below the pile tip plane [2-4].
The quantitative analysis method for karst cave roofs is generally established on the theory of structural mechanics, by which the karst cave roof is simplified into a beam or slab structure according to the fracture distribution around the roof and the pile bottom load. Based on this simplified model, the bending, shear, and punching stability of the roof are checked to determine the vertical bearing capacity of the pile [5]. For instance, Wang et al. [6] presented a formula to calculate the safe thickness of a roof under punching and shearing failure based on the Hoek-Brown failure criterion. Their results showed that different simplified models and constraints have a great influence on the stability of the roof, and fixed and simply supported models represent the upper and lower limits of roof bearing capacity, respectively. Bai [7] improved the calculation method for the safety thickness of karst cave roofs by considering the influence of the weight 
of the karst cave rock mass. Based on three failure modes of karst cave roofs (i.e., bending-tensile failure, shear failure, and punch failure), it was concluded that the thickness of the karst cave roof must be greater than 2.5-3.5 times the diameter of the pile to prevent shear and punch failure and greater than 5.0-5.5 times the diameter of the pile to prevent bending-tensile failure.

Obviously, the key issue for the above analysis methods is selecting an appropriate simplified mechanical model. However, a number of relevant laboratory physical tests have shown that the failure mode of a karst cave roof is generally dominated by punching. For instance, Wyllie [8] studied the failure mode of a double-layered foundation with a hard layer on a soft layer through a large number of load tests and found that even though the maximum principal stress of the hard layer exceeds its tensile strength, there is still no bending-tensile failure; instead, punch failure is the main failure mode. Zhang et al. [9] studied the typical failure modes of karst cave roofs through multiple failure tests and found that roofs with intact rock layers and small thicknesses are prone to punch failure.

A limited analysis method is appropriate for analyzing karst cave roof stability with the punch failure mode. According to this approach, the rock mass of a karst cave roof at the bottom of a pile is assumed to be an ideal rigidplastic body, the punch failure surface is simplified as a very narrow transition zone, and the punch damage body experiences plastic shear flow along the failure surface. Based on the velocity boundary conditions and kinematical compatibility conditions, the equilibrium equation between the external load power and energy dissipation rate of the failure surface is established, and finally, the upper limit of the external load at the bottom of the pile is obtained according to the work-energy equilibrium equation. For instance, Lei et al. [10] established a work and energy equation by combining the Hoek-Brown failure criterion and upper bound analysis method. Their results showed that the punch failure area is a symmetric rotating body with a spiral as the generatrix, and a better quality rock mass for the karst cave roof would require a smaller roof thickness to guarantee its safety. Yin et al. [11] studied a calculation method for the ultimate bearing capacity of a karst cave roof under the actions of axial symmetry and eccentric load based on the Griffith failure criterion and presented a method for estimating the range of punch failure. Their results showed that the ultimate bearing capacity of the roof increases linearly with the thickness of the roof when the eccentricity remains unchanged; however, the ultimate bearing capacity of the roof increases nonlinearly with the eccentricity when the thickness of the roof remains unchanged.

In China's relevant national or local standards, the diameter of the pile is the main influencing factor used to determine the thickness of the karst cave roof, which does not take into account other factors such as the buried depth of the cave, the integrity of the roof rock mass, and the span of the cave. For the sake of simplicity, the thickness of the karst cave roof is generally considered to be no less than three times the diameter of the foundation pile to meet the stability requirements of the roof in practice. Thus, this method for determining the thickness of karst cave roofs based on engineering standards is empirical and nonspecific without considering the rock mass quality and karst cave size [12]. In this study, we present an approach for quantitatively calculating the roof thickness based on the generalized HoekBrown failure criterion by virtue of the limit analysis method, which comprehensively considers the effects of the pile tip load, the hardness degree of the intact rock, and the rock mass quality on the roof thickness. Finally, a physical model test is carried out to verify the validity of the proposed method.

\section{Upper Bound Analysis of Punch Failure Mode of the Karst Cave Roof}

2.1. Generalized Hoek-Brown Failure Criterion. The generalized Hoek-Brown failure criterion is widely accepted to describe the nonlinear failure characteristics of rock masses $[13,14]$, and its equation in principal stress space is shown as [15]

$$
\sigma_{1}=\sigma_{3}+\sigma_{c}\left(\frac{m_{b} \sigma_{3}}{\sigma_{c}}+s\right)^{\alpha},
$$

where $\sigma_{1}$ and $\sigma_{3}$ are the major and minor principal stresses of the rock mass at failure, respectively. $\sigma_{c}$ is the uniaxial compressive strength of the intact rock. $m_{b}, s$, and $\alpha$ are empirical parameters used to reflect the characteristics of different fractured rock masses, which can be expressed as follows $[15,16]$ :

$$
\left\{\begin{array}{l}
m_{b}=\exp \left(\frac{\mathrm{GSI}-100}{28-14 D}\right) m_{i}, \\
s=\exp \left(\frac{\mathrm{GSI}-100}{9-3 D}\right), \\
\alpha=0.5+\frac{1}{6}\left[\exp \left(-\frac{\mathrm{GSI}}{15}\right)-\exp \left(-\frac{20}{3}\right)\right],
\end{array}\right.
$$

where GSI is the geological strength index, which is used to represent the characterization of rock masses on the basis of interlocking and the surface condition of discontinuities, varying from 5 (for a highly fractured and damaged rock mass) to 100 (for intact rock) $[17,18]$. $D$ reflects the degree of influence to which the rock mass has been subjected to blast damage or stress relaxation due to excavation, ranging from 0.0 (for undisturbed in situ rock masses) to 1.0 (for disturbed rock masses) [15]; and $m_{i}$ represents the rock type and hardness, which ranges from 1 to 40 and can be estimated according to the direct tensile test combined with the uniaxial compressive test of intact rock [19]:

$$
m_{i}=\frac{\sigma_{c}}{\sigma_{t}}-\frac{\sigma_{t}}{\sigma_{c}},
$$

where $\sigma_{t}$ is the uniaxial tensile strength of the intact rock.

2.2. Punch Failure Mode of the Karst Cave Roof. In theory, there are three failure modes, i.e., punching failure, shear failure, and bending failure. However, Wyllie [8] stated that punch failure is the main failure mode, and the others are not failure modes, which are concluded from a large number 
of load tests. Thus, this study only takes the punching failure mode of the karst cave roof into account. Figure 1 shows the damage mechanism at the ultimate state of the karst cave roof at the bottom of the pile under the action of a vertical load, in which area I is the punch failure body, area II is the stable cave roof, and area III is the failure discontinuity (i.e., plastic flow zone) with a thickness of $t$. It is noted that area I and area II are both rigid bodies without deformation. $\sigma$ and $\tau$ represent the normal stress and shear stress on the failure discontinuity, respectively. $d$ is the diameter of the pile, and $h$ is the thickness of the karst cave roof at the bottom of the pile. Suppose that punch failure begins at the edge of the pile tip, and the punch damage area is a symmetric body of revolution with the generatrix equation of $r(x)$. Under the action of the ultimate load of the pile tip, the punch failure body moves vertically downward with a velocity of $w$, and the angle between the tangential velocity and the vertical direction of each point on the failure discontinuity is equal to the angle of internal friction $(\varphi)$ at that point. Thus, the normal velocity $v$ and the tangential velocity $u$ of each point on the failure discontinuity can be represented as $w$. $\sin \varphi$ and $w \cdot \cos \varphi$, respectively.

2.3. Upper Limit Solution of the Ultimate Load on the Karst Cave Roof. According to the relationship between the normal stress, shear stress, and principal stress on the failure discontinuity, it can be known that [20]

$$
\left\{\begin{array}{l}
\sigma=\frac{\sigma_{1}+\sigma_{3}}{2}-\frac{\sigma_{1}-\sigma_{3}}{2} \sin \phi, \\
\tau=\frac{\sigma_{1}-\sigma_{3}}{2} \cos \phi .
\end{array}\right.
$$

By substituting (1) into (4), it can be obtained that

$$
\left\{\begin{array}{l}
\sigma=\sigma_{3}+\frac{\sigma_{c}}{2}(1-\sin \phi)\left(\frac{m_{b} \sigma_{3}}{\sigma_{c}}+s\right)^{\alpha}, \\
\tau=\frac{\sigma_{c}}{2} \cos \phi\left(\frac{m_{b} \sigma_{3}}{\sigma_{c}}+s\right)^{\alpha},
\end{array}\right.
$$

According to (5), the relationship between $\sigma$ and $\tau$ can be expressed as

$$
\sigma=\frac{1-\sin \phi}{\cos \phi} \tau+\sigma_{3} .
$$

Moreover, according to (5), $\sigma_{3}$ can be expressed as

$$
\sigma_{3}=\frac{\sigma_{c}}{m_{b}}\left(\sqrt[\alpha]{\frac{2 \tau}{\sigma_{c} \cos \phi}}-s\right) .
$$

By substituting (7) into (6), it can be obtained that

$$
\sigma=\frac{1-\sin \phi}{\cos \phi} \tau+\frac{\sigma_{c}}{m_{b}}\left(\frac{2 \tau}{\sigma_{c} \cos \phi}\right)^{1 / \alpha}-\frac{s \sigma_{c}}{m_{b}} .
$$

Thus, the plastic potential function $(f)$ obeying the generalized Hoek-Brown criterion can be expressed as

$$
f=\sigma-\frac{1-\sin \phi}{\cos \phi} \tau-\frac{\sigma_{c}}{m_{b}}\left(\frac{2 \tau}{\sigma_{c} \cos \phi}\right)^{1 / \alpha}+\frac{s \sigma_{c}}{m_{b}} .
$$

According to the associated flow law, the normal strain rate $\left(\dot{\varepsilon}_{n}\right)$ and tangential strain rate $(\dot{\gamma})$ can be expressed as follows

$$
\left\{\begin{array}{l}
\dot{\varepsilon}_{n}=\lambda \frac{\partial f}{\partial \sigma}=\lambda, \\
\dot{\gamma}=\lambda \frac{\partial f}{\partial \tau}=-\lambda\left[\frac{2}{\alpha m_{b} \cos \phi}\left(\frac{2 \tau}{\sigma_{c} \cos \phi}\right)^{1-\alpha / \alpha}+\frac{1-\sin \phi}{\cos \phi}\right] .
\end{array}\right.
$$

where $\partial$ is the partial derivative function and $\lambda$ is a scale factor [21].

According to the compatible conditions of strain and velocity, the normal strain rate $\left(\dot{\varepsilon}_{n}\right)$ and tangential strain rate $(\dot{\gamma})$ can be expressed as follows:

$$
\left\{\begin{array}{l}
\dot{\varepsilon}_{n}=\frac{\delta w}{t} \sin \phi, \\
\dot{\gamma}=\frac{\delta w}{t} \cos \phi,
\end{array}\right.
$$

where $\delta$ is the derivative symbol [1].

The expressions of $\sigma$ and $\tau$ with respect to $\varphi$ can be obtained by combining (10) and (11):

$$
\begin{aligned}
& \tau=\Psi_{\tau} \sigma_{c}, \\
& \sigma=\Psi_{\sigma} \sigma_{c},
\end{aligned}
$$

where $\Psi_{\tau}$ and $\Psi_{\sigma}$ are expressed as

$$
\left\{\begin{aligned}
\Psi_{\tau} & =\frac{\cos \phi}{2}\left[\frac{\alpha m_{b}}{2 \sin \phi}\left(\sin ^{2} \phi-\cos ^{2} \phi-\sin \phi\right)\right]^{\alpha / 1-\alpha} \\
\Psi_{\sigma} & =\frac{(1-\sin \phi)}{2}\left[\frac{\alpha m_{b}}{2 \sin \phi}\left(\sin ^{2} \phi-\cos ^{2} \phi-\sin \phi\right)\right]^{\alpha / 1-\alpha} \\
& +\frac{1}{m_{b}}\left[\frac{\alpha m_{b}}{2 \sin \phi}\left(\sin ^{2} \phi-\cos ^{2} \phi-\sin \phi\right)\right]^{1 / 1-\alpha}-\frac{s}{m_{b}} .
\end{aligned}\right.
$$

The total energy dissipation rate $W_{\text {int }}$ on the punching break surface can be expressed as 


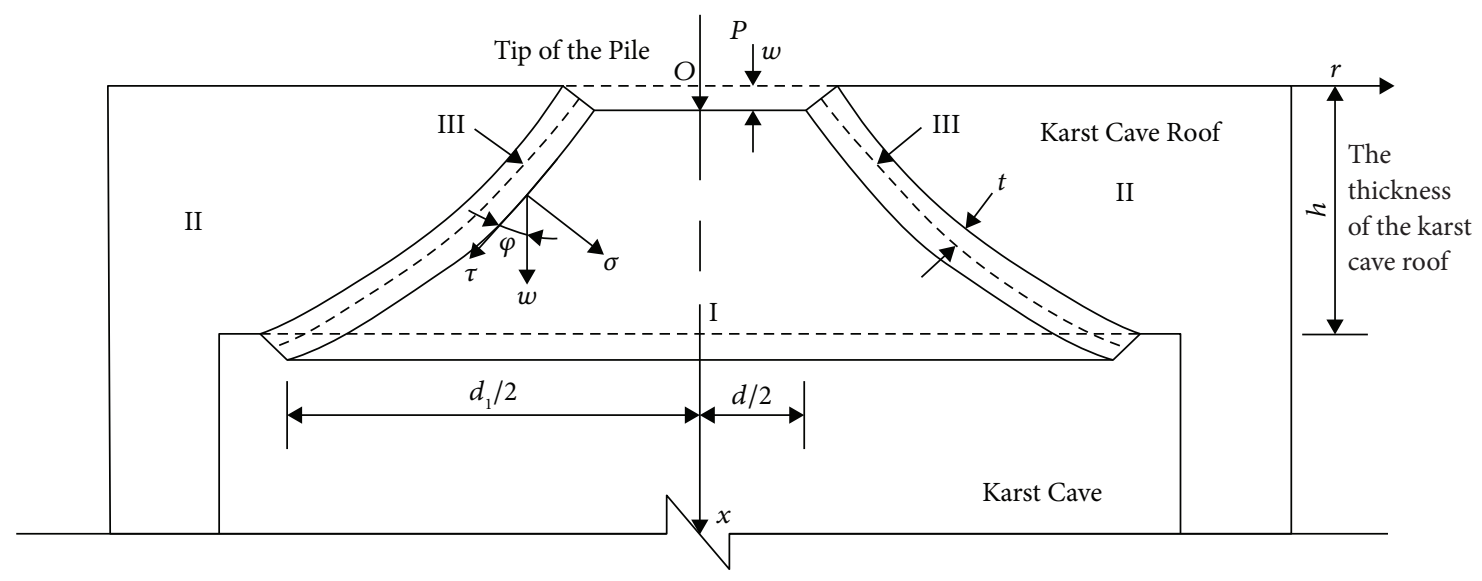

I: Punch failure body II: Stable cave roof
III: Discontinunity of the Punch failure Area I and Area II are regid bodys

Figure 1: Punch failure mode of karst cave roof [10].

$$
\begin{aligned}
W_{\text {int }} & =\left|\int\left(\tau \dot{\gamma}+\sigma \dot{\varepsilon}_{n}\right) t \mathrm{~d} s\right| \\
& =\left|\int\left(\tau \frac{\delta w}{t} \cos \phi+\sigma \frac{\delta w}{t} \sin \phi\right) t \mathrm{~d} s\right| \\
& =\left|\delta w \int(\tau \cos \phi+\sigma \sin \phi) \mathrm{d} s\right| \\
& =\delta w\left|\int_{0}^{h}(\tau \cos \phi+\sigma \sin \phi) \frac{2 \pi r(x)}{\cos \phi} \mathrm{d} x\right|
\end{aligned}
$$

Assuming that the ultimate load at the bottom of the pile is $P$, the external load power $W_{\text {ext }}$ can be expressed as

$$
W_{\mathrm{ext}}=P \delta w \cdot \frac{\pi d^{2}}{4}
$$

According to the upper limit theorem, the external load power is equal to the total internal energy dissipation rate, i.e., $W_{\text {ext }}=W_{\text {int }}$; thus,

$$
P=\frac{8}{d^{2}}\left|\int_{0}^{h} \frac{\tau \cos \phi+\sigma \sin \phi}{\cos \phi} r(x) \mathrm{d} x\right| \text {. }
$$

Assuming that the angle of internal friction is the same at every point on the failure discontinuity surface, the tangent value of the angle between tangential velocity $u$ and vertical velocity $w$ is equal to a constant value $\tan \varphi$. Therefore, the equation of the generatrix is expressed as follows:

$$
r(x)=\frac{d}{2}+\tan \phi \cdot x .
$$

By substituting (17) into (16), $P$ is finally expressed as

$$
\begin{aligned}
P & =\frac{4(\tau \cos \phi+\sigma \sin \phi)}{\cos \phi}\left[\tan \phi\left(\frac{h}{d}\right)^{2}+\frac{h}{d}\right] \\
& =\frac{4 \sigma_{c}\left[\Psi_{\tau} \cos \phi+\Psi_{\sigma} \sin \phi\right]}{\cos \phi}\left[\tan \phi\left(\frac{h}{d}\right)^{2}+\frac{h}{d}\right] .
\end{aligned}
$$

The internal friction angle of the rock mass can be estimated based on the generalized Hoek-Brown criterion, i.e., [15]

$$
\phi=\sin ^{-1}\left[\frac{6 \alpha m_{b}\left(s+m_{b} \sigma_{3 n}\right)^{\alpha-1}}{2(1+\alpha)(2+\alpha)+6 \alpha m_{b}\left(s+m_{b} \sigma_{3 n}\right)^{\alpha-1}}\right],
$$

where $\sigma_{3 n}=\sigma_{3 \max } / \sigma_{c}$. Note that, $\sigma_{3 \max }$ is the upper limit of confining stress over which the relationship between the generalized Hoek-Brown and the Mohr-Coulomb criterion is considered. For the homogeneous rock masses, the equivalent friction angle $\varphi$ is a constant, and (17) can then be simplified as a straight line. Otherwise, if each point on the discontinuity has a different $\varphi$, (17) would be a curve. In particular, suppose that the span of the karst cave is $D_{r}$, and $r(h)=0.5 d h \cdot \tan \varphi$ is greater than or equal to $0.5 D_{r}$, which means that the base diameter of the punch failure body would be greater than or equal to the span of the karst cave; thus, punch failure can only start from the edge of the pile tip and end at the top edge of the karst cave. Finally, the tangential value of the angle between the punch failure discontinuity and the vertical direction is expressed as

$$
\tan \phi=\frac{0.5\left(D_{r}-d\right)}{h} .
$$

In the design of a rock-socketed pile, the ultimate tip resistance $P$ can be estimated according to the uniaxial compressive strength of the rock $\sigma_{c}$, i.e., [22]

$$
P=\psi_{r} \cdot \sigma_{c},
$$

where $\psi_{r}$ is the reduction coefficient. For intact rock, $\psi_{r}=0.5$. For a relatively intact rock mass, $\psi_{r}=0.2-0.4$. For a heavily fractured rock mass, $\psi_{r}=0.1$.

\section{Calculation of the Critical Thickness-to- Diameter Ratio of the Karst Cave Roof}

The karst cave roof thickness $(h)$ and pile diameter $(d)$ are two significant factors that affect the stability of a karst cave roof. In this study, we define an index $\eta$ (i.e., $\eta=h / d$, the ratio 
of karst cave roof thickness to pile diameter) to represent the stability of the karst cave roof. A greater value of $\eta$ means that the karst cave roof has a higher stability. When the karst cave roof is in a critical failure state, the value of $\eta$ is called the critical thickness-to-diameter ratio. A function of the critical thickness-to-diameter ratio $\eta$ can be obtained by combining (18) with (21), i.e.,

$$
\tan \phi \cdot \eta^{2}+\eta-\frac{\psi_{r} \cos \phi}{4\left[\Psi_{\tau} \cos \phi+\Psi_{\sigma} \sin \phi\right]}=0,
$$

where $\eta$ is equal to $h / d$.

According to equation (2), the parameters involved in the generalized Hoek-Brown criterion $m_{b}, s$, and $\alpha$ are functions of the GSI, $m_{i}$, and $D$. Due to the rock mass located at the end of the pile, it is assumed that the disturbance to the rock mass is very slight, and $D$ is assigned to 0 . Thus, by taking different values of GSI, $m_{i}$, and $\psi_{r}$, a series of quadratic equations in one unknown with respect to $\eta$ can be established, and the critical thickness-to-diameter ratio under different rock mass qualities can be obtained by solving the quadratic equations.

The value of $m_{i}$ for the chemical sedimentary rock is suggested to vary from 3 to $15[23,24]$; thus, its value is assigned to $\{3,6,9,12,15\}$ in this study. GSI varies from 0 to 100, and thus, its value is assigned to $\{10,20,30,40,50,60,70,80,90,100\}$ in this study. In addition, the value of $\psi_{r}$ is assigned to $\{0.1,0.2,0.3,0.4,0.5\}$. Finally, the curved surfaces of $\eta$ under different values of $\psi_{r}$ are shown in Figures 2-6. According to Figures 2-6, $\eta$ decreases monotonically as GSI and $m_{i}$ increase, which indicates that a better rock mass quality could lead to a smaller value of $\eta$, and a harder rock mass could also lead to a smaller value of $\eta$. In addition, the value of $\eta$ increases with increasing $\psi_{r}$, indicating that a larger ultimate tip resistance could lead to a larger value of $\eta$.

According to the characteristics of the curved surfaces, the following equation is used for fitting the data to build the relationships between $\eta$ and the combination of $m_{i}$ and GSI under different values of $\psi_{r}$. The fitting results are shown in Table 1, and the correlation coefficients are all greater than 0.99 , indicating that the fitted equation could well represent their relationship.

$$
\eta=\frac{p_{1}}{p_{2}+p_{3} \cdot m_{i}+p_{4} \cdot \mathrm{GSI}+m_{i} \cdot \mathrm{GSI}},
$$

where $p_{1}, p_{2}, p_{3}$, and $p_{4}$ are fitting coefficients. Obviously, the critical thickness-to-diameter ratio could be directly obtained by combining (23) with Table 1, which does not require complicated calculations using (13)-(22).

\section{Physical Model Test}

4.1. Experimental Design. In fact, the shape of the real karst cave is irregular; however, the indexes to evaluate the size of the karst cave are often the span and the height. In the model test, it is impossible to completely simulate the shape of a real karst cave. Thus, we simplify it as a semicylindrical cavity, which contains the indexes of the span and height. Figure 7

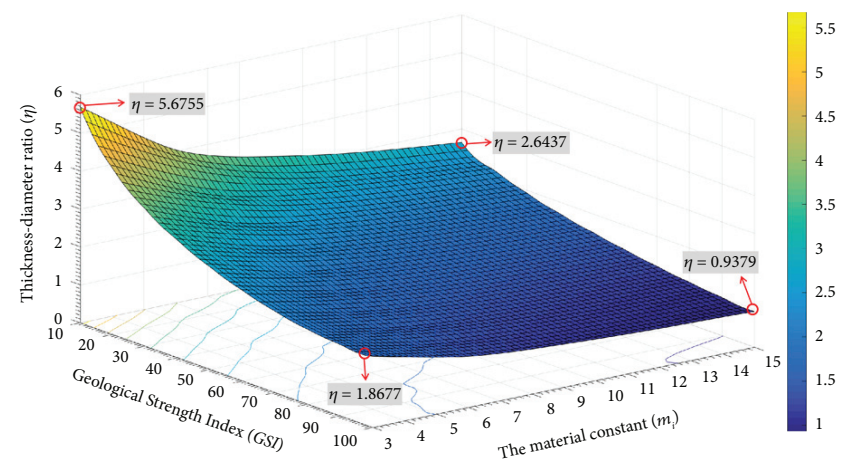

FIGURE 2: Curved surface of critical thickness-to-diameter ratio under the condition of $\psi_{r}=0.1$.

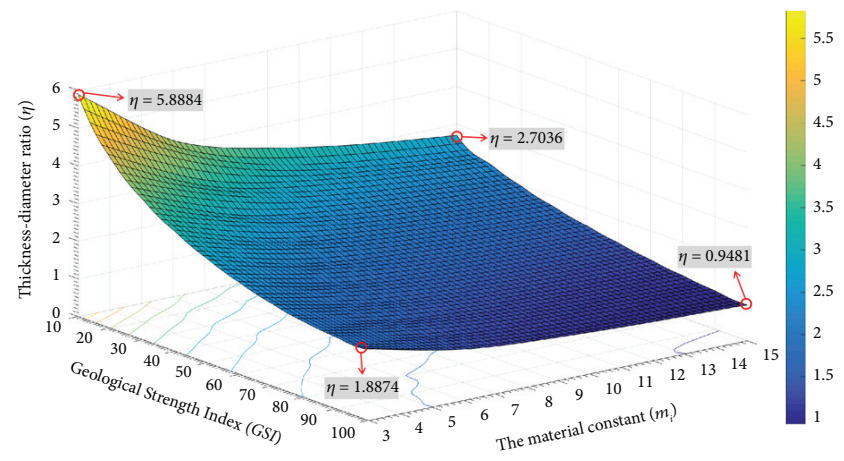

Figure 3: Curved surface of critical thickness-to-diameter ratio under the condition of $\psi_{r}=0.2$.

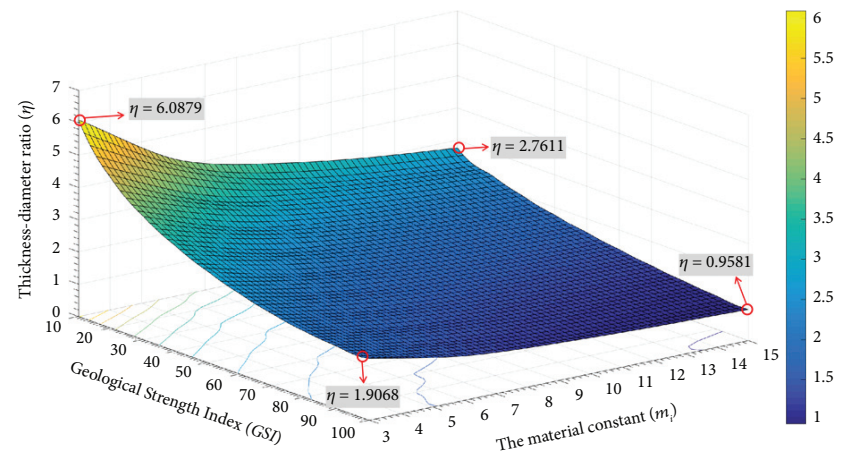

Figure 4: Curved surface of critical thickness-to-diameter ratio under the condition of $\psi_{r}=0.3$.

shows a diagram of the physical model used in this study, and the entire model is simplified as a symmetrical structure. The stratum is composed of two layers, i.e., overlying soil and underlying bedrock. The karst cave is located at the underlying bedrock and is simplified as a semicylindrical cavity with a diameter of $D_{r}=30 \mathrm{~cm}$ and height $H=15 \mathrm{~cm}$. The pile is simplified as a semicylinder with a diameter of $d=5 \mathrm{~cm}$, and it is located above the karst cave with a distance of $3 d$ from the bottom of the pile to the top of the karst cave. In this study, we use mixtures of cement, sand, gypsum, and water in a certain proportion as similar materials to pour the overlying soil, underlying bedrock, and socketed pile. The 


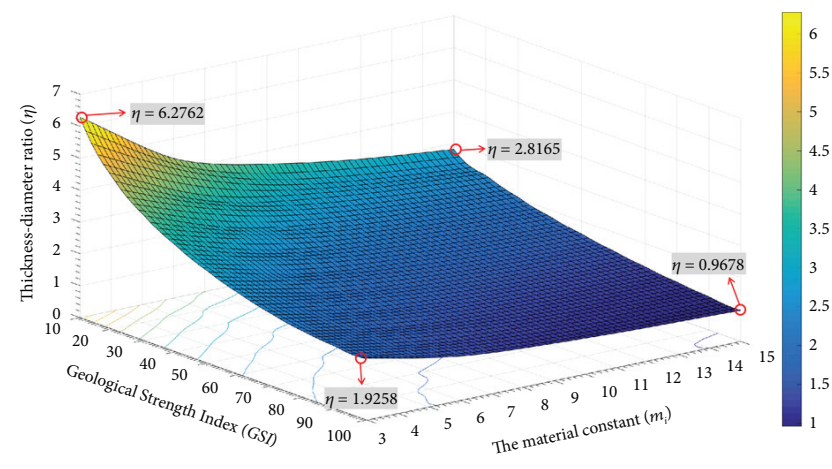

FIGURE 5: Curved surface of critical thickness-to-diameter ratio under the condition of $\psi_{r}=0.4$.

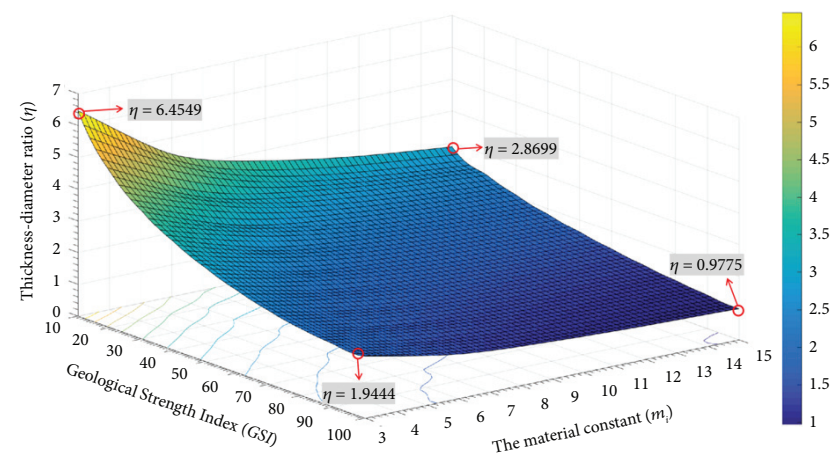

FIgURE 6: Curved surface of critical thickness-to-diameter ratio under the condition of $\psi_{r}=0.5$.

TABLe 1: The fitting results under the different values of $\psi_{r}$.

\begin{tabular}{cccccc}
\hline$\psi_{r}$ & $p_{1}$ & $p_{2}$ & $p_{3}$ & $p_{4}$ & $\begin{array}{c}\text { Correlation } \\
\text { coefficient }\end{array}$ \\
\hline 0.1 & 4061.8141 & 346.6466 & 64.9156 & 16.6719 & 0.9954 \\
0.2 & 4093.2221 & 324.4172 & 64.8682 & 16.6512 & 0.9956 \\
0.3 & 4118.0682 & 305.4965 & 64.6015 & 16.5798 & 0.9958 \\
0.4 & 4138.9451 & 289.2287 & 64.2061 & 16.4789 & 0.9959 \\
0.5 & 4157.4294 & 275.1117 & 63.7373 & 16.3613 & 0.9961 \\
\hline
\end{tabular}

proportion of mixtures and the corresponding mechanical properties are shown in Table 2. The socketed pile is prefabricated by placing the similar material into a semicylinder container with a diameter of $d=5.0 \mathrm{~cm}$ and a length of $L=42.5 \mathrm{~cm}$, and the overlying soil and underlying bedrock are constructed layer by layer by placing the similar material into a semisymmetric model test chamber with a size of $1.25 \mathrm{~m} \times 1.25 \mathrm{~m} \times 0.625 \mathrm{~m}$ (length $\times$ height $\times$ width). A semicylinder with the same size as the karst cave is buried in the designated position of the model test tank, and it is removed from the tank after curing the similar material for 12 hours. In addition, the prefabricated pile is installed above the roof of the karst cave, and a similar material is placed to surround it. Figure 8 shows the pouring process of the physical model.

4.2. Results and Analysis of Experiments. To simulate the failure process of the roof of the karst cave by physical model testing, we use a jack to apply graded loading to the top of the pile with $500 \mathrm{~N}$ for each grade. Once the roof of the cave is damaged, the loading on the pile top is terminated. During the loading process, the earth pressure cell is installed at the bottom of the pile to monitor the normal stress simultaneously to acquire the pile bottom ultimate load. Figure 9 shows the curve of the pile bottom load. There is a significant mutation on this curve, and the maximum pile bottom load is approximately equal to $0.16 \mathrm{MPa}$, indicating that the vertical load transmission mostly depends on the side friction of the pile before the mutation point and that the vertical load is mainly transmitted to the pile bottom at the mutation point. Thus, the pile bottom ultimate load is considered to be $0.16 \mathrm{MPa}$.

Figure 10 shows the final failure mode of the karst cave roof under the vertical load of the pile. Obviously, it is a typical punch failure mode, and the punch failure body is a semisymmetric cone with a base diameter of $18.0 \mathrm{~cm}$ and a top diameter of $6.0 \mathrm{~cm}$. For this physical experiment, we consider that the relevant parameters of the generalized Hoek-Brown criterion corresponding to the underlying bedrock are as follows: $\sigma_{c}=0.25 \mathrm{MPa}, \mathrm{GSI}=100, m_{i}=1.0$, $D=0.0$. In addition, the real thickness-to-diameter ratio of the karst cave roof $h / d$ is 3.0 , and the reduction coefficient $\psi_{r}$ is considered to be 0.5 because the underlying bedrock is intact (i.e., GSI $=100$ ). Thus, according to equation (18), we could acquire the calculated value of the pile bottom ultimate load of $0.203 \mathrm{MPa}$, which is slightly greater than the actual monitored value $(0.16 \mathrm{MPa})$. It is indicated that the proposed method could provide a relatively accurate calculation method for the pile bottom ultimate load. In addition, according to equation (23), we can obtain that the critical thickness-to-diameter ratio of the karst cave $(\eta)$ is 2.036 , which is less than the real thickness-to-diameter ratio of the karst cave roof $h / d$. This is because equation (21) $\left(P=\psi_{r} \times \sigma_{c}\right)$ is used to estimate the pile bottom ultimate load to deduce the calculation equation of $\eta$. In this study, $P=\psi_{r} \times \sigma_{c}=0.5 \times 0.25=0.125 \mathrm{MPa}$ is less than the truly measured ultimate load $0.16 \mathrm{MPa}$. It is concluded that the result from equation (23) is relatively conservative.

\section{A Project Case}

Figure 11 shows the borehole columnar section of a real project case. The depth of the cave is approximately $25 \mathrm{~m}$ from the ground surface, the height of the cave is $2.27 \mathrm{~m}$, the thickness of the roof of the cave is $0.72 \mathrm{~m}$, the crossing of the cave is $5.0 \mathrm{~m}$, and the diameter of the foundation pile is $0.8 \mathrm{~m}$. According to the measured data, the mechanical parameters of each soil layer and foundation pile are as follows:

(a) The characteristic values of pile side friction of each soil layer above the roof of the karst cave are as follows: plain filling soil $12 \mathrm{kPa}$, hard plastic clay $42 \mathrm{kPa}$, plastic clay $34 \mathrm{kPa}$, coarse sand $32 \mathrm{kPa}$, silty soil $10 \mathrm{kPa}$, plastic silty clay $10 \mathrm{kPa}$, and hard plastic silty clay $34 \mathrm{kPa}$.

(b) The roof rock mass of the karst cave is moderately breeze fossil limestone with a density of $2710 \mathrm{~kg} / \mathrm{m}^{3}$ 


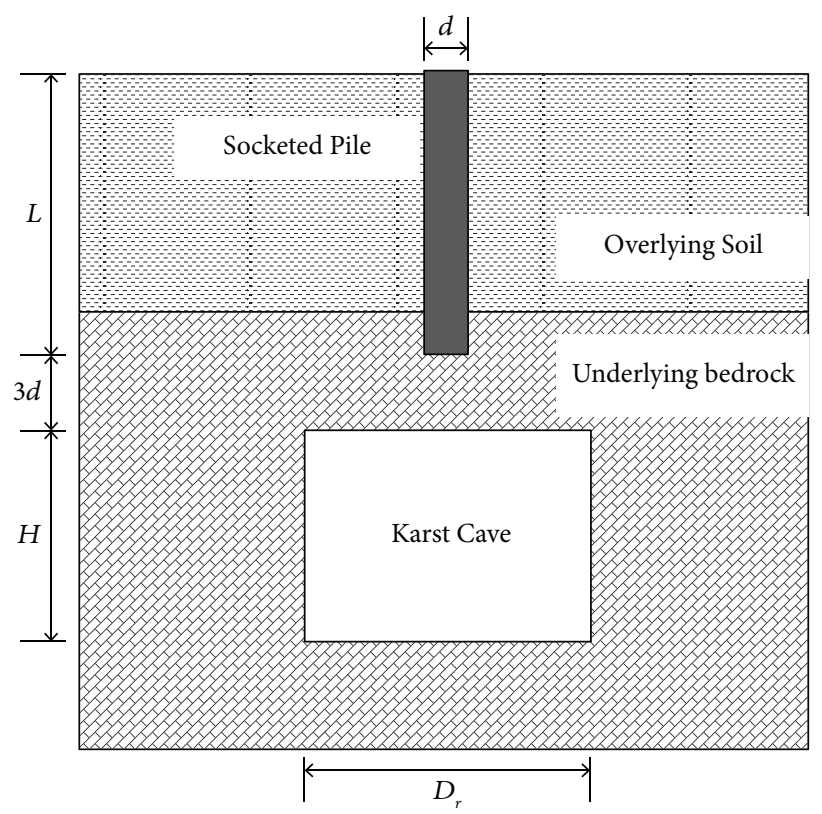

FIGURE 7: Diagram of the physical model test.

TABLE 2: Mix proportion and mechanical properties of the similar material.

\begin{tabular}{lcccc}
\hline Similar material & $\begin{array}{c}\text { Unit weight } \\
\left(\mathrm{kN} / \mathrm{m}^{3}\right)\end{array}$ & Uniaxial compressive strength $(\mathrm{MPa})$ & Mass ratio of cement, sand and water Gypsum content (\%) \\
\hline Socketed pile & 21.3 & 1.02 & $1: 5.2: 1.5$ & 2 \\
Overlying soil & 19.6 & 0.06 & $1: 15: 1.5$ & 1 \\
Underlying bedrock & 20.3 & 0.25 & $1: 8: 1.5$ & 1 \\
\hline
\end{tabular}

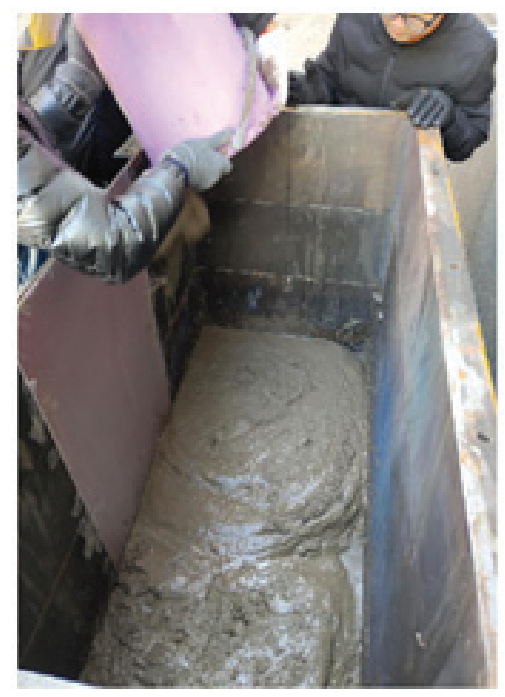

(a)

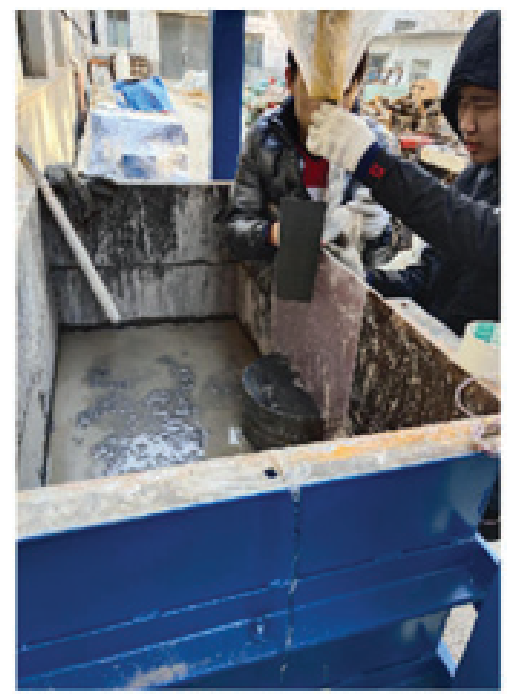

(b)

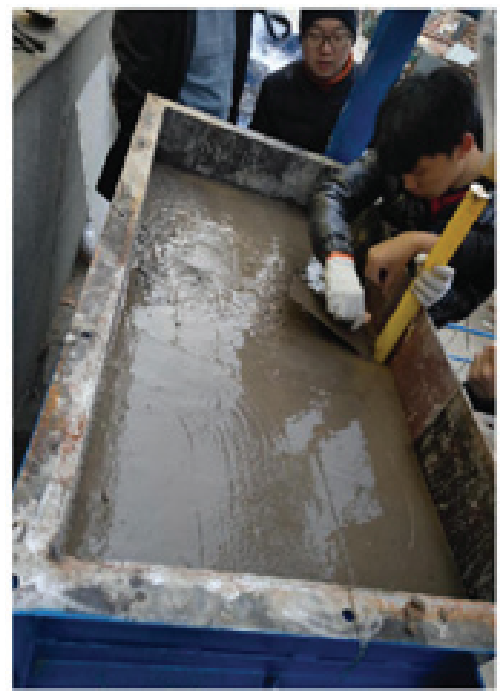

(c)

Figure 8: Continued. 


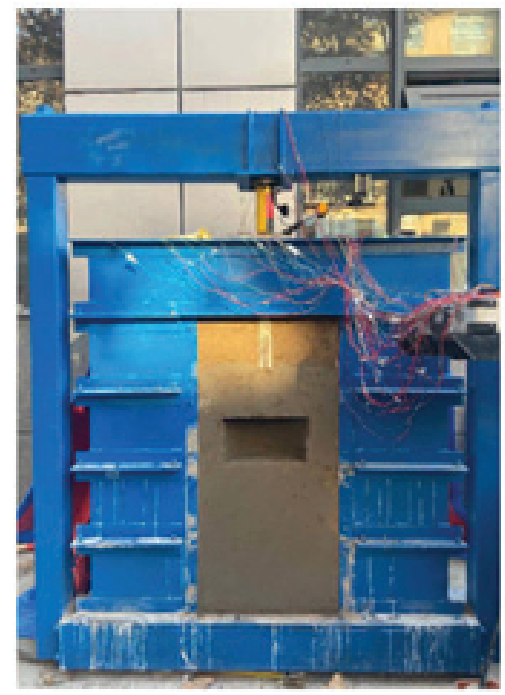

(d)

Figure 8: The process of constructing the physical model. (a) Pouring the similar material, (b) pre-burying the semicylinder, (c) installing the socketed pile, and (d) completing the physical model.

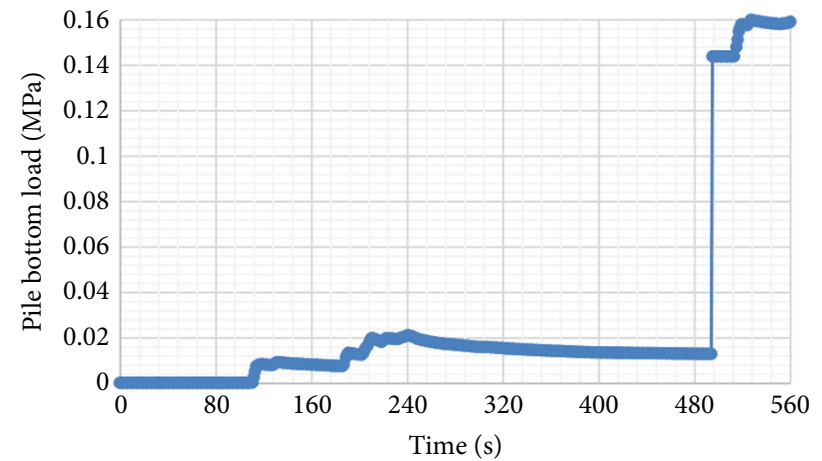

FIgURE 9: The curve of pile bottom load during the loading process.

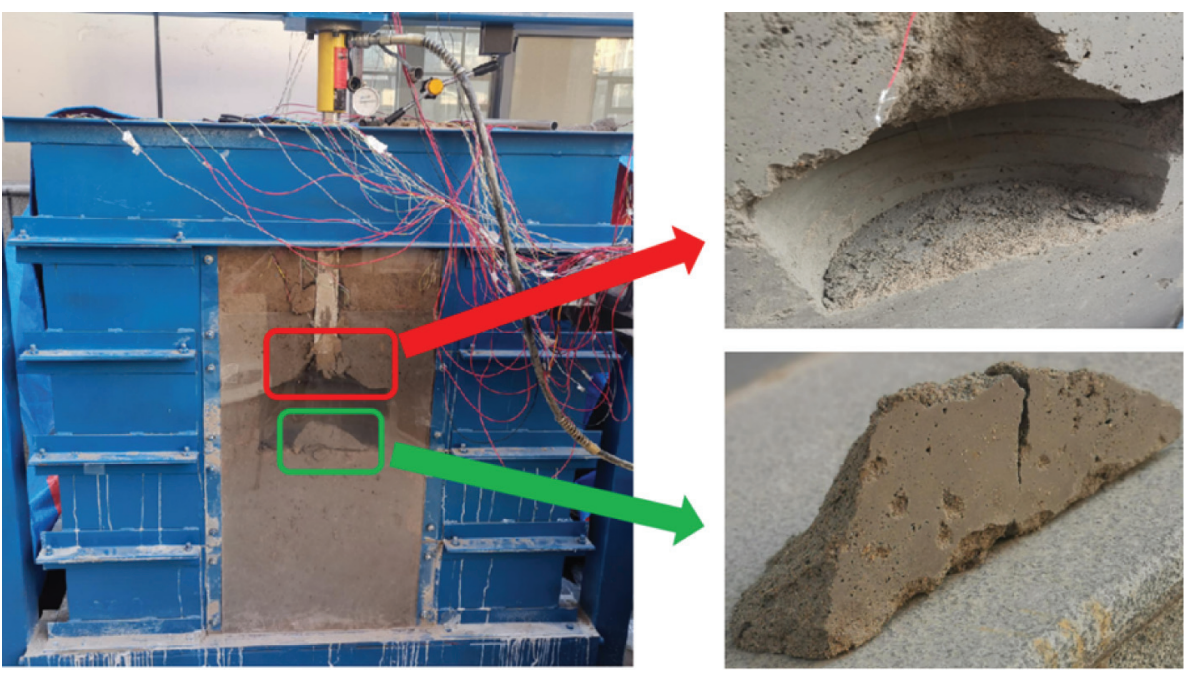

Figure 10: The final failure mode of the karst cave roof. 


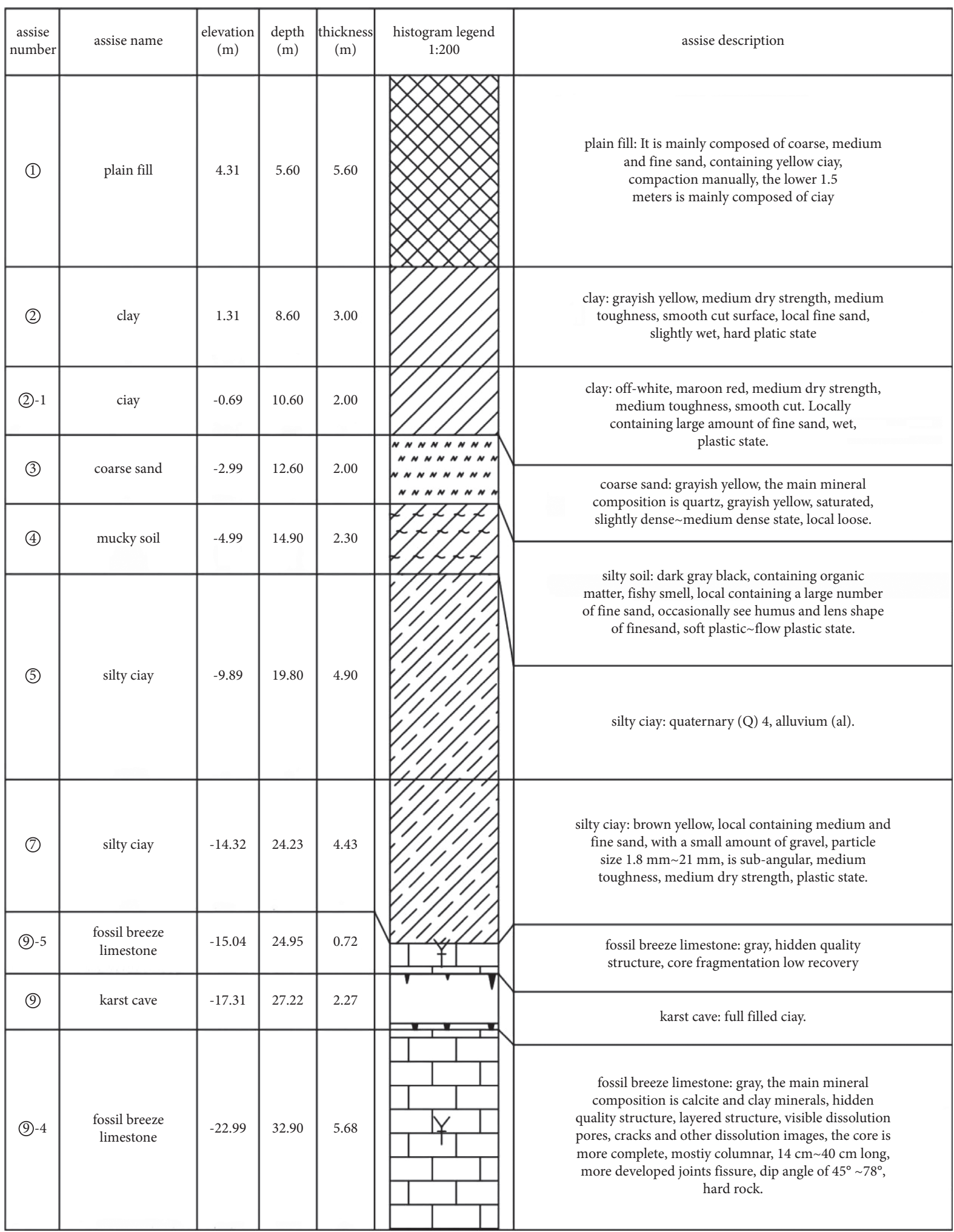

FIgURE 11: Borehole columnar section.

and a uniaxial compressive strength $\left(\sigma_{c}\right)$ of $100 \mathrm{MPa}$. The integrity of the roof rock mass is poor, and its integrity index $\left(K_{v}\right)$ is 0.3 based on the field wave velocity test.
According to [23] method for taking the value of the material constant $m_{i}$, we can conclude that $m_{i}$ for limestone is approximately 9.0 in this study. According to $K_{v}=0.3$, the roof rock mass is classified as a fractured rock mass. In 
addition, the weathering degree of the roof rock mass is weak weathering. By virtue of [17] GSI scoring system, we can conclude that the GSI of the roof rock mass is approximately 60.0 in this study. According to the integrity of the roof rock mass, the reduction coefficient $\psi_{r}$ in (21) is recommended to be 0.2 in this study. Thus, the fitting coefficients $p_{1}, p_{2}, p_{3}$, and $p_{4}$ in $(23)$ are 4093.2221, 324.4172, 64.8682, and 16.6512, respectively, referring to Table 1.

Thus, the critical thickness-to-diameter ratio of this project case is calculated to be 1.67 according to (23). Finally, the critical thickness of the karst cave roof is calculated to be $1.34 \mathrm{~m}$, which is greater than the real thickness of $0.72 \mathrm{~m}$. It is indicated that the real thickness of the karst cave roof cannot sufficiently provide bearing capacity for the pile foundation. To improve the ultimate bearing capacity of foundation piles, it is necessary for foundation piles to penetrate the cave roof and embed it into the bottom of the cave to a certain depth.

The ultimate bearing capacity of the field test pile is $8000 \mathrm{kN}$ after the foundation pile penetrates through the karst cave. Assuming that the foundation pile does not cross the roof of the karst cave and the pile end is set at the interface between the roof of the karst cave and the silty clay (that is, the depth embedded into the breezed rock mass is zero), the ultimate lateral friction of pile body $Q_{s k}$ can be calculated, i.e.,

$$
Q_{s k}=2 \pi r \sum q_{\mathrm{sik}} l_{i}
$$

where $q_{\text {sik }}$ and $l_{i}$ represent the ultimate lateral resistance and the thickness of the $i^{\text {th }}$ layer of soil around the pile, respectively. Thus, $Q_{s k}=2 \times 3.14 \times 0.4 \times(12 \times 5.6+42 \times 3+34 \times 2+32 \times 2$ $+10 \times 2.3+10 \times 4.9+34 \times 4.43)=1376 \mathrm{kN}$.

In addition, the total ultimate resistance of the pile tip $Q_{r k}$ can be calculated, i.e.,

$$
Q_{r k}=\zeta_{r} \sigma_{\text {cmass }} \frac{\pi}{4} d^{2}
$$

where $\zeta_{r}$ is the comprehensive effect coefficient of the end resistance and is recommended to be 0.6 according to the PRC National Standard [22] and $\sigma_{\text {cmass }}$ is the uniaxial compressive strength of the fractured rock mass and can be calculated, i.e.,

$$
\sigma_{\text {cmass }}=\sigma_{c} s^{\alpha} .
$$

According to equation (2), $s$ is calculated to be 0.0117 and $\alpha$ is calculated to be 0.5057 ; thus, $\sigma_{\text {cmass }}=100 \times 0.0117^{0.5057}$ $=10.564 \mathrm{MPa}, \quad Q_{r k}=0.6 \times 10564 \times 3.14 \times 0.25 \times 0.8 \times 0.8=$ $3186 \mathrm{KN}$. Finally, the ultimate bearing capacity of the foundation pile from the theoretical calculation is $4562 \mathrm{kN}$ (i.e., $4562 \mathrm{kN}) . Q_{s k}+Q_{r k}$, which is less than the ultimate bearing capacity of the field test pile of $8000 \mathrm{kN}$. This indicates from another point of view that the roof of the cave cannot provide sufficient bearing capacity, and it is necessary for foundation piles to penetrate the cave roof.

\section{Conclusions}

In this study, we present an estimation method to calculate the critical thickness-to-diameter ratio of a karst cave roof $\eta$ $(\eta=h / d$, the ratio of karst cave roof thickness to pile diameter) by combining the generalized Hoek-Brown criterion with the limit analysis method, which considers the influence of the span of the karst cave and the rock mass quality. Finally, we use a physical test to verify the validity of the proposed method. The main conclusions are as follows:

(1) The reduction coefficient $\left(\psi_{r}\right)$, the rock type and hardness $\left(m_{i}\right)$, and the geological strength index (GSI) have a significant influence on the critical thickness-to-diameter ratio of the karst cave roof $\eta$, and $\eta$ can be expressed as a hyperbolic function of $m_{i}$ and the GSI for different $\psi_{r}$. The results show that a better rock mass quality, a harder intact rock, and a smaller ultimate load lead to a smaller value of $\eta$.

(2) The validity of the proposed method is verified by the physical model test. The failure mode of the karst roof is an obvious punch failure mode, and the failure body is a semisymmetric cone. The results show that the pile bottom ultimate load resulting from the proposed method is close to that of the real measured value. $[25,26]$.

\section{Data Availability}

Some or all data, models, or codes generated or used during the study are available from the corresponding author upon request.

\section{Conflicts of Interest}

The authors declare that they have no conflicts of interest.

\section{Acknowledgments}

The authors gratefully acknowledge the support of Hebei Province Science Foundation for Outstanding Yong Scientists (no. E2021210041), Key Foundation of Education Department of Hebei Province (no. ZD2020333), and Hebei Natural Science Foundation (E2021210128).

\section{References}

[1] B. X. Yuan, Z. H. Li, Z. Q. Zhao, H. Ni, Z. L. Su, and Z. J. Li, "Experimental study of displacement field of layered soils surrounding laterally loaded pile based on Transparent Soil," Journal of Soils and Sediments, vol. 21, pp. 3072-3083, 2021.

[2] H. L. Liu and M. H. Zhao, "Review of ground improvement technical and its application in China," China Civil Engineering Journal, vol. 49, no. 1, pp. 96-115, 2016.

[3] F. Zhou, W. Qu, and J. Chen, "Engineering practice on Endbearing composite pile foundation in Karst area," Chinese Journal of Underground Space and Engineering, vol. 12, no. 2, pp. 489-494, 2016.

[4] B. Bai, R. Zhou, G. Cai, W. Hu, and G. Yang, "Coupled thermo-hydro-mechanical mechanism in view of the soil particle rearrangement of granular thermodynamics," Computers and Geotechnics, vol. 137, no. 8, Article ID 104272, 2021.

[5] M. H. Zhao, Y. Lei, and R. Zhang, "Study of punching failure mode and safe thickness of pile foundation in karst region," Rock and Soil Mechanics, vol. 33, no. 2, pp. 524-530, 2012. 
[6] H. B. Wang, Z. F. Liu, W. F. Zhao, B. Zhou, and J. W. Li, "Research on stability of cave roof under pile loading in bridge construction engineering," Chinese Journal of Rock Mechanics and Engineering, vol. 32, no. s2, pp. 3650-3657, 2013.

[7] H. J. Bai, "A method for calculating the safety rock thickness of pile bearing strata with considering deadweight of karst cave roof," Rock and Soil Mechanics, vol. 37, no. 10, pp. 2945-2952, 2016.

[8] D. C. Wyllie, Foundations on Rock, pp. 36-46, Chapman \& Hall, London, UK, 1992.

[9] H. L. Zhang, Z. H. Zhang, and S. H. Wang, "Experimental study and analysis of rock-socketed pile in karst area," China Civil Engineering Journal, vol. 46, no. 1, pp. 92-103, 2013.

[10] Y. Lei, Q. N. Chen, and B. F. Ma, "Punching analysis of rock at pile tip base on limit analysis," Chinese Journal of Rock Mechanics and Engineering, vol. 37, no. 3, pp. 631-638, 2014.

[11] J. F. Yin, Y. Lei, Q. N. Chen, Y. X. Liu, and J. Z. Deng, "Upper bound analysis of the punching shear failure of cave roof in karst area," Rock and Soil Mechanics, vol. 39, no. 8, pp. 1-7, 2018.

[12] W. Yuan, S. G. Liu, Q. K. Nie, and W. Wang, "An approach for determining the critical thickness of the karst cave roof at the bottom of socketed pile based on punch failure mode," Rock and Soil Mechanics, vol. 40, no. 7, pp. 1-10, 2019.

[13] S. Xie, H. Lin, Y. Wang, R. Cao, R. Yong, and S. Du, "Nonlinear shear constitutive model for peak shear-type joints based on improved Harris damage function," Archives of Civil and Mechanical Engineering, vol. 20, 2020.

[14] Y. Chen, H. Lin, X. Ding, and S. Xie, "Scale effect of shear mechanical properties of non-penetrating horizontal rocklike joints," Environmental Earth Sciences, vol. 80, no. 5, 2021.

[15] E. Hoek, C. T. T. Carranza, and B. Corkum, "Hoek-Brown failure criterion-2002 edition," in Proceedings of the Fifth North American Rock Mechanics Symposium (NARMS-TAC), pp. 267-273, University of Toronto Press, Toronto, Canada, January 2002.

[16] E. Erik, "The Hoek-Brown failure criterion," Rock Mechanics and Rock Engineering, vol. 45, pp. 981-988, 2012.

[17] H. Sonmez and R. Ulusay, "Modifications to the geological strength index (GSI) and their applicability to stability of slopes," International Journal of Rock Mechanics and Mining Sciences, vol. 36, no. 6, pp. 743-760, 1999.

[18] W. Yuan, J. X. Li, Z. H. Li, W. Wang, and X. Y. Sun, "A strength reduction method based on the Generalized HoekBrown (GHB) criterion for rock slope stability analysis," Computers and Geotechnics, vol. 117, Article ID 103240, 2020.

[19] K. Colak and T. Unlu, "Effect of transverse anisotropy on the Hoek-Brown strength parameter 'mi' for intact rocks," International Journal of Rock Mechanics and Mining Sciences, vol. 41, no. 6, pp. 1045-1052, 2004.

[20] B. Bai, G. Yang, T. Li, and G. Yang, "A thermodynamic constitutive model with temperature effect based on particle rearrangement for geomaterials," Mechanics of Materials, vol. 139, Article ID 103180, 2019.

[21] B. Bai, D. Rao, T. Chang, and Z. Guo, "A nonlinear attachment-detachment model with adsorption hysteresis for suspension-colloidal transport in porous media," Journal of Hydrology, vol. 578, Article ID 124080, 2019.

[22] PRC National Standard, "Code for design of building foundation GB 50007-2011," 2011, https://www.chinesestandard. net/PDF.aspx/GB50007-2011.

[23] E. Hoek and E. T. Brown, "Practical estimates of rock mass strength," International Journal of Rock Mechanics and Mining Sciences, vol. 34, no. 8, pp. 1165-1186, 1997.
[24] P. Marinos and E. Hoek, "Estimating the geotechnical properties of heterogeneous rock masses such as flysch," Bulletin of Engineering Geology and the Environment, vol. 60, no. 2, pp. 85-92, 2001.

[25] B. X. Yuan, Z. H. Li, Z. L. Su, Q. Z. Luo, M. J. Chen, and Z. Q. Zhao, "Sensitivity of multistage fill slope based on finite element model," Advances in Civil Engineering, vol. 2021, Article ID 6622936, 13 pages, 2021.

[26] B. X. Yuan, Z. H. Li, Y. M. Chen et al., "Mechanical and microstructural properties of recycling granite residual soil reinforced with glass fiber and liquid-modified polyvinyl alcohol polymer," Chemosphere, vol. 286, Article ID 131652, 2021. 